\title{
EL IMPACTO DEL LIBERALISMO EN LAS CALLES DE ALICANTE DURANTE EL SIGLO XIX*
}

\author{
Víctor Sánchez Martín
}

\section{Introducción}

El presente trabajo tiene como objeto de estudio el impacto que tuvo en el callejero alicantino el liberalismo, que transformó el espacio público en un campo de lucha política y pedagogía nacional, y cuál fue la evolución del uso político del paisaje urbano. Para ello utilizaremos diversas fuentes, desde planos y callejeros hasta las propias actas municipales, con lo que podemos obtener una muestra parcial del callejero en momentos históricos clave. Mantendremos como hipótesis de trabajo inicial que las calles y plazas sólo varían de nombre en coyunturas políticas de cambio; pese a todo existen importantes problemas a la hora de abordar la cuestión. A las faltas de información y la imposibilidad de abarcar la totalidad del callejero de cada momento, se une la visión oficial obtenida, que lleva a que determinadas barriadas existentes no se tengan en cuenta en un momento dado o que queden reflejados nombres de calles que sólo tenían validez sobre el papel, puesto que se continuaron utilizando los nombres anteriores sin que ese uso real haya pervivido en la mayor parte de las fuentes.

La evolución de la nomenclatura de las calles es una cuestión poco trabajada $^{1}$, pero que puede ofrecer interesantes reflexiones, puesto que relaciona

\footnotetext{
* Esta investigación ha sido realizada gracias a una Beca de Iniciación a la Investigación del Vicerrectorado de Investigación y Desarrollo de la UA (Resolución de 18 de julio de 2007), ref. BII2007-74005729.

1. Debemos destacar los siguientes trabajos, con gran variedad de enfoques metodológicos: BALAGUER, V., Las calles de Barcelona; origen de sus nombres, sus recuerdos, sus tradiciones y leyendas; biografía de los personajes ilustres, Barcelona, 1866 (facsímil 1987); BOIX, V., Valencia histórica y topográfica; relación de sus calles, plazas y puertas, origen de sus
} 
aspectos de la geografía histórica con la historia cultural y política. Con el advenimiento del liberalismo, la utilización del espacio urbano cambió profundamente y las calles pasaron a ser escenario de violentos combates por la memoria y la socialización de las masas. La evolución del uso de la nomenclatura de las calles durante la revolución liberal nos mostrará aspectos interesantes de la cambiante relación entre el callejero y la sociedad en función del contexto sociopolítico.

\section{Guerra y revolución}

A lo largo del siglo XVIII Alicante experimentó un proceso general de crecimiento, contando a inicios del siglo XIX con unos 20.000 habitantes. Hasta 1807, la ciudad mantuvo las murallas construidas con anterioridad a 1704, que protegían todo el casco histórico, incluyendo los barrios de San Roque, Santa Cruz, Villavieja y el importante arrabal de San Francisco, quedando fuera el arrabal de San Antón. En 1807 comenzaron las obras de amurallamiento del Tossal, que culminaron con la creación del denominado castillo de San Fernando, un baluarte en realidad, terminado en 1812. Así, entre junio de 1808 y octubre de $1809^{2}$ comenzaron las nuevas obras de la muralla, destinadas a su mejora y reforzamiento, lo que tendría importantes efectos sobre el urbanismo alicantino, puesto que el nuevo cerco abarcaba parte del territorio rural hasta entonces fuera de la zona amurallada; terreno que serviría para la planificación del Barrio Nuevo.

El callejero alicantino a inicios del siglo XIX mostraba un carácter tradicional, puesto que tras la Guerra de la Independencia, Alicante no tenía un callejero sustancialmente diferente al existente a lo largo de la segunda mitad del siglo XVIII. Los cambios en esos 60 años no debieron ser muy numerosos,

nombres, hechos célebres ocurridos en ellas y demás noticias importantes relativas a esta capital, Imprenta de J. Rius, Valencia, 1863 (facsímil 1979); Colle, M., Rues, places et cours de Bordeaux pendant la Révolution, Pimientos, Urrugne, 2005; GIMÉNEZ, E. «Paseo por las calles de Alicante», Diario Información, 14 de septiembre de 2008; MARTíNEZ LóPEz, M., Alicante, la historia a través de sus calles, Club Universitario, Alicante, 2000; Mesonero Romanos, R., El antiguo Madrid, paseos histórico-anecdóticos por las calles y casas de esta villa, Madrid, 1881; NAVARro NAVARro, J., «Las calles cambian de nombre», en Navarro NaVARro, J., Valencia, capital de la República, tomo 7 de Girona A. y SANTACREU, J.M. (dirs.), La Guerra Civil en la Comunidad Valenciana, Editorial Prensa Valenciana, Valencia, 2006, pp. 94-103; SERrano, C., El nacimiento de Carmen. Símbolos, mitos y nación, Taurus, Madrid, 1999, pp. 161-182; VIDAL TUR, G., Alicante, sus calles antiguas y modernas, Gráficas Vidal-Leuka, Alicante, 1974.

2. Rosser Limiñana, P., Origen y evolución de las murallas de Alicante, Patronato Municipal del V Centenario de la ciudad de Alicante, Alicante, 1990, p. 156. 
Cuadro 1. Cambios de nombre tras la guerra (1814)

\begin{tabular}{|l|l|}
\hline Nombre antiguo & Nuevo nombre \\
\hline Virgen del Remedio (1803) & Remedio \\
\hline Plaza del Pescado (1794) & Pescadería \\
\hline Alpargateros (1794) & Santos Médicos \\
\hline Portal de Elche (1754) & Plaza de la Constitución \\
\hline
\end{tabular}

y los encontrados (ver cuadro $1^{3}$ ) responden a la lógica popular tendente al acortamiento de los nombres de las calles o el cambio de denominación por cuestiones socioprofesionales o luchas de prestigio. La excepción será el caso del Portal de Elche, verdadera plaza mayor que capitalizaba gran parte de la vida de la ciudad, siendo el eslabón de paso entre la ciudad antigua y el barrio de San Francisco.

La Plaza de la Constitución nos ofrece el primer ejemplo emblemático de utilización simbólica del paisaje urbano, siendo el único cambio de nombre de tipo político del periodo. Con esta plaza la localidad alicantina glorificaba el experimento que se había producido en 1812 en España y se significaba claramente a su favor, dedicando para ello un espacio privilegiado, puesto que tras la construcción de la nueva muralla en plena guerra, esta plaza ganó un importante valor al formar el eje de comunicación entre el casco antiguo y la ciudad nueva. Así se cumplía la Real Orden del 14 de agosto por la que las Cortes Generales decretaban que la Plaza General de todos los pueblos de España en los que se hubiera promulgado la Constitución debía ser denominada Plaza de la Constitución ${ }^{4}$.

Sin embargo, el 15 de mayo de 1814 Fernando VII firmaba el decreto de anulación de la Constitución. El cabildo alicantino ordenó que «inmediatamente se quite y destruya la lápida de la Constitución de Cádiz que se colocó en la Plaza de Elche» ${ }^{5}$. Viravens nos indica que en la misma tarde del 15 de mayo

3. Todos los cuadros son producto de una base de datos de elaboración propia a partir de las siguientes fuentes: Padrón Extraordinario realizado por Emilio Jover en 1814 (A.M.A., arm. 5, lib. 107); MARTínez Morellá, V., Nomenclátor de las vías públicas de Alicante en 1754, Artes Gráficas Alicante, Alicante, 1954; Plano de Alicante e inmediaciones levantado por Manuel Miralles en 1794 (A.M.A. Sección Mapas, Grabado n ${ }^{\circ}$ 530); Plano de la ciudad de Alicante. 1853, levantado por Francisco Coello (A.M.A, Sección Mapas, Plano n ${ }^{\circ}$ 769); Plano de la ciudad de Alicante (1881) (A.M.A., Sección Mapas, Plano n ${ }^{\circ}$ 760); Plano de la Ciudad de Alicante (circa 1913) (A.M.A., Sección Mapas, Plano ${ }^{\circ} 748$ ) junto con los cabildos citados.

4. A.M.A., Cabildo 3 de octubre de 1812, arm. 9, lib. 107, fol. 178.

5. A.M.A., Cabildo 15 de mayo de 1814, arm. 9, lib. 109, fol. 120 v. 
los alicantinos arrancaron «con el mayor júbilo» la lápida constitucional ${ }^{6}$. Cabe resaltar el carácter simbólico del acto, puesto que la piedra destrozada fue colocada en el ataúd destinado para cadáveres de pobres y conducida por las calles en forma de entierro hasta que se lanzó la caja a una acequia del Malecón. Así se enterraba la lápida de la Constitución, y con ella, lo que ésta representaba. Pronto un vecino, Juan Marchent, pidió que se colocara otra lápida con el nombre de Plaza de Fernando VII, indicando además que él mismo tenía ya la pieza preparada, pidiendo permiso para colocarla ${ }^{7}$. El 30 de mayo se produjo la solemne colocación de la lápida que entronizaba el nombre de Plaza Real de Fernando VII ${ }^{8}$.

Si valoramos globalmente el callejero alicantino, comparando el Padrón Extraordinario realizado por Emilio Jover en $1814^{9}$ con el nomenclátor de $1754^{10}$, comprobamos como el primero refleja la sociedad del Antiguo Régimen. El 72,5\% de las denominaciones de 1754 seguían perviviendo en 1814, representando el 58,6\% de la ciudad que encaraba el siglo XIX. A su vez, otro $20 \%$ de la ciudad de 1814 estaba compuesta por las denominaciones surgidas en los momentos finales del Antiguo Régimen. Por todo ello tenemos que hablar de continuidad a la hora de estudiar el callejero alicantino de 1814.

Pero no sólo debemos estudiar el callejero en su aspecto cuantitativo, si no también en su aspecto cualitativo. ¿A qué hacían referencia los nombres de las calles? Para estudiar este aspecto, clasificaremos las calles en diversas tipologías. Por ejemplo, en 1754 encontramos un 62,5\% de registros de tipo funcional. Con ello nos referimos a calles que en su denominación aluden a elementos físicos de la calle o a las actividades que allí se realizaban. El 27,5\% de las calles eran de tipo religioso, refiriéndose a santos fundamentalmente. Por último, tenemos un $10 \%$ de calles que habría que calificar de tipo político-tradicional. Si aplicamos el mismo análisis al callejero de 1814 podemos ver cómo el aprovechamiento simbólico del espacio urbano se mantiene en proporciones similares. De los 87 registros constatados, el 50,5\% hacen referencia a denominaciones funcionales, el 35,6\% son de tipo religioso y únicamente el 13,7\% pueden ser calificados como de tipo político-tradicional. Así, la denominación callejera aún no había sido monopolizada por el poder como instrumento al servicio de la política.

6. Viravens y Pastor, R., Crónica de la ciudad de Alicante, Ayuntamiento de Alicante, Alicante, 1989, p. 391.

7. A.M.A., Cabildo 16 de mayo de 1814, arm. 9, lib. 109, fol. 125.

8. A.M.A., Cabildo 20 de mayo de 1814, arm. 9, lib. 109, fol. 131.

9. A.M.A., op. cit.

10. Martínez Morellá, V., op. cit. 
En un momento de escasa uniformidad urbanística, las diferencias entre unas calles y otras eran tan notables como para generar los propios nombres. Por ello encontramos nombres que reflejan las características físicas de las calles (Arriba, Empedrado, Barranquet, Entre dos puertas, En medio, Entre muro y muro, Hondo, Parque, Puente, Villavieja, Plaza del Puente, Norte, Troncos). Pero también encontramos calles con nombres de tipo funcional que hacen referencia a las actividades de la calle, caso de las del Horno, Pescadería, Labradores, Lonja de Caballeros, Toneleros, Balseta, Diezmo, Plaza de la Fruta, Plaza de las Barcas, Parque, Parador, Pelota o Navío.

Asimismo destacan los nombres de santos y vírgenes, más de la mitad del total. Finalmente, hay que reseñar algunos nombres de tipo político-tradicional (Marsella, Valencia, Morelló, Rovira, Sevila) que no se encuadran bajo los supuestos anteriores, puesto que muestran procesos de utilización política primitiva del espacio urbano. Es el caso de las calles Marsella o Valencia, presentes desde mediados del siglo XVIII; si la segunda era una concesión a la geografía regional, la primera revela el papel de los comerciantes franceses, que gozaron siempre del favor de la oligarquía gobernante ${ }^{11}$. La novedad del periodo queda representada por la Plaza de la Constitución, apropiación clara del paisaje urbano con un fin pedagógico y nacionalizador, que nos ofrece una novedad frente al panorama anterior; una modificación de las coordenadas ideológico-sociales en que se movía el callejero. Este avance inauguró las luchas por el espacio urbano.

Tras el fin de la guerra destaca el deseo municipal por derribar la muralla del Vall, en la actual Rambla Méndez Núñez. Las obras se iniciaron en 1821 y en el lugar donde había estado la muralla se creó un paseo elevado que se convirtió en reflejo de los valores de las nuevas costumbres urbanas de las clases dominantes ${ }^{12}$.

Con la llegada del Trienio Liberal, el Ayuntamiento volvió a denominar como Plaza de la Constitución a la antigua Plaza Real de Fernando VII. El régimen liberal tenía en esas plazas toda su nueva simbología, siendo revelador que en febrero de 1822, cuando los absolutistas ensuciaron la lápida de la Constitución, los regidores alicantinos no pudieron ser más explícitos al calificar a esa lápida como «el sagrado símbolo de nuestra libertad» ${ }^{13}$. También se cambiaron tres nombres de calles, mostrando la vuelta de la Plaza de la

11. A.A.V.V., Historia de Alicante, Tomo I, Ayuntamiento de Alicante, Alicante, 1989, pp. 445-446.

12. Calduch Cervera, J., La ciudad nueva, Patronato Municipal del Quinto Centenario de la ciudad de Alicante, Alicante, 1990, pp. 64-66.

13. A.M.A., Cabildo 25 de febrero de 1823, arm. 9, lib. 117, fols. 71v-72. 
Constitución, el bautismo como Paseo de Quiroga al paseo surgido tras el derribo de la muralla del Vall, y la rotulación con el nombre de Riego de la antigua calle de la Muralla (ver mapa 1). Clara es la intención de generar un espacio urbano simbólico, puesto que desde la Plaza de la Constitución se podía ir hacia el norte por el Paseo de Quiroga, importante lugar de recreo y vía de comunicación con todo el casco histórico. Por otro lado, se podía ir por la calle de Riego hacia el Ayuntamiento. Con ello se estaban dando nombres de gran significado político al eje vertebrador de la ciudad.

Tras la derrota militar frente a las tropas de Angulema, los liberales arrancaron las lápidas dedicadas a Quiroga, Riego y la Constitución para evitar su ultraje $^{14}$. Con el retorno del absolutismo, llegó el rápido cambio de nombre para las vías urbanas, para lo que se utilizaron lápidas provisionales. El 1 de diciembre, el cabildo alicantino de signo absolutista acordaba que la calle de Riego pasara a ser denominada de Angulema, y que el Paseo de la Reina recuperara para la monarquía el espacio urbano usurpado por Quiroga. Pero reconquistar el espacio profanado no era suficiente, y por ello se hicieron pedazos públicamente las lápidas liberales, arrojando posteriormente los restos al mar, «a distancia proporcionada» ${ }^{15}$. El 21 de abril de 1824 se dispuso una gran fiesta para celebrar la colocación de la lápida en la renombrada Plaza Real de Fernando VII.

En 1829, el gobernador militar de la ciudad, Iriberri, mejoró las condiciones del Paseo de la Reina, mediante la plantación de álamos, la colocación de bancos y la construcción de una fuente y una glorieta arbolada ${ }^{16}$, mostrando el interés por configurarlo como espacio de recreo y festejos. Y es que desde 1830, momento en que el paseo estuvo terminado, se convirtió en el lugar preferido para la celebración de verbenas, que hasta ese momento habían sido actividades extraordinarias. Así comenzaron a celebrarse dos veces por semana veladas musicales en dicho lugar; costumbre que pervivió hasta el último tercio del siglo XIX, puesto que en 1887 se trasladarían al Paseo de los Mártires $^{17}$. Es esencial destacar la importancia del paseo como manifestación de la sociabilidad burguesa y del ascenso social. Así, no bastaba con enriquecerse, sino que había que demostrarlo. Por otro lado, el paseo era el paso previo a la

14. VIRAVENS Y PASTOR, R., op. cit., p. 421.

15. A.M.A., Cabildo 29 de noviembre de 1823, arm. 9, lib. 117, fol. 501v.

16. VIRAVENS Y PASTOR, R., op. cit., p. 444.

17. Vidal Tur, G., Alicante ochocentista, Alicante, 1967, p. 127. 
posibilidad de intercambios privados entre las elites; todo dentro de un marco de ostentación ${ }^{18}$, lo que explica la importancia social del paseo.

\section{El triunfo del liberalismo}

Tras la muerte de Fernando VII los principios liberales fueron consolidándose paulatinamente y el 10 de agosto de 1836 las autoridades alicantinas juraran el código constitucional recién proclamado, la Constitución de 1812. A las cinco de la tarde se llevó a cabo la publicación oficial y el juramento solemne de la nueva ley en la hasta entonces Plaza Real de Fernando VII. El recuerdo de ese lugar como la Plaza de la Constitución ya había llevado a los alicantinos más exaltados a proclamar el texto constitucional allí la noche anterior ${ }^{19}$. En 1839 ya se había dedicado una plaza a Isabel $\mathrm{II}^{20}$, que no era otra que la conocida tradicionalmente como Plaza de las Barcas ${ }^{21}$. Las celebraciones por el fin de la guerra civil tuvieron lugar tanto en la Plaza de la Constitución y el Paseo de la Reina como en la recién creada Plaza de Isabel II, que se asociaba tanto con la Constitución como con el triunfo bélico (ver mapa 2).

También destaca la construcción del Teatro Nuevo, cuya primera piedra se colocó el 28 de enero de 1846 en la Plaza del Barranquet, que pese a su situación periférica era una zona de paso esencial. La construcción del Teatro allí nos muestra el papel de centralidad reservado al Barrio Nuevo, ya que «la burguesía comercial alicantina de principios del siglo XIX veía la construcción de un teatro a sus expensas como la plasmación de un deseo de autoidentificación ${ }^{22}$. La importancia del Teatro para las elites hizo que poco después se cambiara el nombre de la plaza, por su carácter de representación del poder burgués, puesto que más allá de su función artística, el teatro se muestra como un lugar de identidad social y cultural de la burguesía ${ }^{23}$.

18. PONS, A., SERNA, J., La ciudad extensa. La burguesía comercial-financiera en la Valencia de mediados del XIX, Diputació de Valencia, Valencia, 1992, pp. 215-220.

19. Camilo Jover, N., Reseña histórica de la ciudad de Alicante, Alicante, 1863, pp. 176177. El autor recrea con detalle las celebraciones que tuvieron lugar por la promulgación de la Constitución y por el fin de la guerra carlista, mostrando el papel simbólico de la plaza.

20. Ibídem, NOTAS, p. 82.

21. Esta plaza pasó a conocerse entonces como Plaza de Isabel II oficialmente, pero el nombre popular mantuvo su arraigo, por lo que convivieron las dos denominaciones hasta la intervención de la Comisión de Ornato en 1852.

22. Calduch Cervera, J., op. cit., pp. 95, 98, 99.

23. Mcdonogh, G. W., Las buenas familias de Barcelona. Historia social de poder en la era industrial, Ediciones Omega, Barcelona, 1986, pp. 242-264. 
Cuadro 2. Novedades 1836-1851

\begin{tabular}{|l|l|l|}
\hline Funcional & Religiosa & Política \\
\hline Aliaga & Santa Faz & Bendicho \\
\hline Bóvedas & Divina Pastora & Montalvo \\
\hline Delicias & San Juan & Aparicio \\
\hline Vista alegre & Santa Marta & Blasco \\
\hline Muro & Virgen del Grito & Aranjuez \\
\hline Rincón & Santa Bárbara & Artilleros \\
\hline Molino & Monjas & Reina \\
\hline Montañeta & & Puerta de la Reina \\
\hline Diluvio & & Princesa \\
\hline & & Triunfo \\
\hline & & Victoria \\
\hline & & San Fernando \\
\hline & & Bilbao \\
\hline & & Riego \\
\hline
\end{tabular}

Desde 1844 hasta 1854, como en el resto de España, los moderados ostentarían el poder en Alicante marcando con una fuerte impronta política, social y cultural a la ciudad ${ }^{24}$. Ello tuvo un reflejo parcial en el callejero, puesto que tenemos constancia de 30 nuevos nombres de calles, legislados con anterioridad a 1852, que nos muestran cómo en los momentos iniciales de la implantación del liberalismo convivieron los imaginarios políticos de moderados y progresistas (ver cuadro 2). Mientras que las denominaciones religiosas y funcionales se estancan, se produce un nítido avance de la tipología política, ligada a la coyuntura política de los años 30.

Encontramos un programa de glorificación monárquica con la rotulación de las calles Reina, Puerta de la Reina o la sustitución del Duque de Angulema por la calle Princesa. A su vez, Riego recuperó su calle, en una de las nuevas vías del Barrio Nuevo. La victoria bélica también se conmemoró en el callejero y la exaltación monárquica quedó ligada a la victoria frente a los carlistas, lo que explica la presencia de las calles de la Victoria, del Triunfo y Bilbao, situadas en paralelo y desembocando en el Malecón, que crean un espacio urbano

24. ROMEO, M. C., «Tras los escombros de la revolución. El moderantismo y las estrategias políticas y culturales de dominación», en FuenteS, J. F. y ROURA, Ll., Sociabilidad y liberalismo en la España del siglo XIX. Homenaje a Alberto Gil Novales, Ed. Milenio, Lleida, 2001, pp. 239-261; Díaz MARín, P., Después de la revolución. Centralismo y burguesía en Alicante (1844-1854), Institut de Cultura Juan Gil-Albert, Alicante, 1998. 
dedicado al recuerdo de la victoria bélica. A su vez, se inició la tradición localista liberal, como podemos comprobar en las calles Aparicio y Bendicho. Si la primera recordaba al famoso pintor alicantino (lo que permitió olvidar su condición de pintor de cámara de Fernando VII), la segunda hacía referencia al eclesiástico que escribió la conocida crónica sobre Alicante.

Pero la verdadera transformación del paisaje urbano alicantino llegaría en 1852, momento en que se emprendió el cambio del nombre de 62 calles sobre un total aproximado de 125, es decir, el 49,6\% del callejero. Así, se llevó a cabo un profundo proceso de renovación de la nomenclatura de las vías de la ciudad, que contaba entonces con 19.650 habitantes; más aún si tenemos en cuenta que casi el $70 \%$ de las novedades reciben un nombre de tipo político. Gracias al acta municipal del 7 de octubre de $1852^{25}$ conocemos el parecer de la Comisión de Ornato, encargada de las cuestiones relacionadas con la policía urbana. Se presentó la lista de los nombres de las 15 plazas y 125 calles que componían la ciudad añadiendo las modificaciones pertinentes por la necesidad de cambiar algunos nombres «ya por la ninguna significación que tienen unos, ya por la repugnancia que otros ofrecen», lo que nos muestra la preocupación existente por actualizar esas denominaciones para que respondieran a los referentes liberales.

La acción de la Comisión de Ornato motivó que únicamente se conservaran 33 nombres de calles de la ciudad del Antiguo Régimen. Este exiguo $26,4 \%$ de vías que se mantuvieron tuvo plena vigencia como mínimo entre 1754 y 1814, y probablemente fue ese arraigo, que las situaba dentro de lo tradicional, lo que explica su pervivencia. En este sentido hay que destacar que el $67 \%$ de estos nombres que se mantienen ya estaban presentes en 1754 . Por otra parte, resulta sintomático que el 55\% de los nombres que se mantienen sean religiosos, lo que explica su pervivencia desde el siglo XVIII, y un 36\% denominaciones funcionales, explicable por la propia configuración urbana que garantizaba su existencia.

En cuanto a los cambios de nombre de las plazas, salvo el recuerdo del baluarte de San Carlos en una denominación funcional, el resto de cambios tuvo una motivación política (ver cuadro 3). Se entronizaba la figura local de Campoamor en el casco urbano, toda vez que ya se había inaugurado en 1849 su paseo situado extramuros. Gobernador Civil de la provincia y poeta, fue nombrado Hijo Adoptivo de la ciudad y elegido diputado a Cortes en 1850 en la provincia. Artífice del paseo que llevaba su nombre, hizo valer su influencia para la construcción de la línea férrea y otras mejoras de la ciudad.

25. A.M.A., Cabildo 7 de octubre de 1852, arm. 9, lib. 151. 
Cuadro 3. Cambios Plazas 1852

\begin{tabular}{|l|l|}
\hline Nombre antiguo & Nombre nuevo \\
\hline Plaza del Barranquet & Plaza del Teatro \\
\hline Plaza de San Agustín & Plaza de Campoamor \\
\hline Plaza de la Fruta & Plaza del Progreso \\
\hline Plaza de las Barcas & Plaza de Isabel II \\
\hline Calle del Mar & Plaza de San Carlos \\
\hline
\end{tabular}

Por otro lado, se consagraba el ideal de progreso con una plaza muy cercana al Ayuntamiento, ocupando con una idea profundamente nueva un espacio tradicional. Finalmente, el Teatro como manifestación burguesa por excelencia también tuvo su plaza. En cuanto a la Plaza de Isabel II, si había convivido con la denominación tradicional de Plaza de las Barcas, a la altura de 1852 ya no se hace referencia al nombre tradicional, mostrando el control institucional sobre estas cuestiones.

Los nombres de calles escogidos para sustituir los antiguos muestran los nuevos intereses. Así, únicamente se legislaron 4 cambios de tipo funcional (ver cuadro 4), lo que evidencia que esa tipología tenía un carácter popular incompatible con los intereses oficiales.

Se legislaron 15 cambios de nombre religiosos (ver cuadro 5), un $24,1 \%$ del total, sustituyendo a denominaciones funcionales en su mayoría. La mayor parte de estos cambios se concentraron en el barrio de Santa Cruz, reflejando cómo se consideró que el casco antiguo era el lugar más adecuado para conceder espacio a las denominaciones religiosas. Ello revela el distinto uso de las calles en función de su importancia y situación, puesto que no era lo mismo renombrar calles con un carácter tradicional que rotular por vez primera calles recién creadas. Esta notable presencia religiosa en el callejero debe entenderse por la sintonía de los moderados con los intereses religiosos, ejemplificado en la firma del Concordato de 1851 con la Santa Sede.

Cuadro 4. Cambios funcionales 1852

\begin{tabular}{|l|l|}
\hline Nombre antiguo & Nombre moderno \\
\hline Asegurada & Instituto \\
\hline Teatro antiguo & Niágara \\
\hline Peregrinos & Aduana \\
\hline Hospicio & Jerusalem \\
\hline
\end{tabular}


Cuadro 5. Cambios religiosos 1852

\begin{tabular}{|l|l|}
\hline Nombre antiguo & Nombre moderno \\
\hline Brosa & San Isidro \\
\hline Portalet & Santo Tomás \\
\hline Empedrado & San Andrés \\
\hline San Ginés & San Miguel \\
\hline San Juan de la Cruz & San Luis \\
\hline Barranco del Carmen & San Rafael \\
\hline Ciegos & Santa Lucía \\
\hline Figuereta & San Bartolomé \\
\hline Trampa & San Bartolomé \\
\hline Aduana & San Telmo \\
\hline Pescadería & Cruz de Malta \\
\hline Balseta & Calatrava \\
\hline Pantoni & Santiago \\
\hline Esteras & San Isidro \\
\hline Norte & San Pedro \\
\hline
\end{tabular}

Pero fueron las modificaciones de tipo político las protagonistas del periodo, ya que comprenden 43 de los 62 variaciones legisladas por la Comisión de Ornato, un $69,3 \%$ del total (ver cuadro 6). Esa cifra nos permite comprender la magnitud de la transformación operada en el paisaje urbano. Conocido es el papel que para los legisladores liberales podía jugar la historia a la hora de conformar una conciencia nacional ${ }^{26}$, por lo que ahora estudiaremos su plasmación en Alicante, ya que las modificaciones obedecieron a diversos referentes históricos.

Entre esos referentes podemos encontrar desde aquellos que se remontaban al Medievo para buscar la forja de la nación, pasando por el recuerdo de la época imperial (siendo fundamental la mítica España de los Reyes Católicos); hasta aquellos que apelaban al mundo de la cultura como elemento nacionalizador, puesto que se intentaba acercar al pueblo a los valores nacionales a través de los valores culturales ejemplificados por los grandes literatos. Por último, son fundamentales los imaginarios que entroncan con el derecho de resistencia y sus mártires y la Guerra de Independencia.

26. Álvarez Junco, J., Mater Dolorosa. La idea de España en el siglo XIX, Taurus, Madrid, 2001, pp. 195 y 196. 
Cuadro 6. Cambios políticos 1852

\begin{tabular}{|c|c|}
\hline Nombre antiguo & Nombre moderno \\
\hline \multicolumn{2}{|c|}{ La forja de la nación durante el Medievo } \\
\hline Gigantes & Tarifa \\
\hline Parador & Cid \\
\hline Ancha & Navas \\
\hline \multicolumn{2}{|c|}{ Las glorias imperiales } \\
\hline Mar & Cisneros \\
\hline Coche & Antequera \\
\hline Porchinos & León \\
\hline Porchinos & Pizarro \\
\hline Cerdán & Toledo \\
\hline Escalera de Marbeuf & Subida de la calle Toledo \\
\hline Almas & San Quintín \\
\hline San Vicente & Colón \\
\hline \multicolumn{2}{|c|}{ Los hijos ilustres de Alicante y su gloriosa historia } \\
\hline San Juan de Dios & Montengón \\
\hline Agullón & Cienfuegos \\
\hline San José & Álvarez \\
\hline Coallas & Barceló \\
\hline Pescadería vieja & Roger \\
\hline Miguel Carratalá & Coloma \\
\hline Escalambre & Ojeda \\
\hline Cabeseros & Rivera \\
\hline- & Lucentum \\
\hline \multicolumn{2}{|c|}{ La Guerra de la Independencia } \\
\hline Aranjuez & San Ildefonso \\
\hline Foso & Gerona \\
\hline Barranquet & Bailén \\
\hline Callejón de las Monjas & Duque de Zaragoza \\
\hline Rejas & Castaños \\
\hline Postiguet & Gravina \\
\hline Entre dos puertas & Infanta \\
\hline Troncos & Velarde \\
\hline \multicolumn{2}{|c|}{ El derecho a la resistencia y los mártires de la libertad } \\
\hline Avellán & Padilla \\
\hline Lobo & Maldonado \\
\hline Buda & Lanuza \\
\hline
\end{tabular}

Pasado y Memoria. Revista de Historia Contemporánea, 7, 2008, pp. 189-218 


\begin{tabular}{|c|c|}
\hline Sevila & Viriato \\
\hline Horno & Valdés \\
\hline Igualdad & Torrijos \\
\hline Isla & Bazán \\
\hline \multicolumn{2}{|c|}{ Cultura y nación } \\
\hline Arques y San Elías & Argensola \\
\hline Arquet & Luzán \\
\hline Torreta & Quevedo \\
\hline Torreta & Villegas \\
\hline Soledad & Zorrilla \\
\hline Ataúd & Moratín \\
\hline Toneleros & Jorge Juan \\
\hline Correo Viejo & Guzmán \\
\hline
\end{tabular}

Otro grupo a reseñar es el de los hijos pródigos de Alicante. El espacio reservado en el callejero para éstos es esencial, puesto que el liberalismo sentó las bases de la organización provincial como una nueva forma de entender la nación recién creada. Se entendía la recuperación del pasado propio como una forma de hacer patria española, evitando así la excluyente identificación entre la nación y Castilla; preocupación que no se tuvo en Alicante por el enfrentamiento larvado con Valencia, que hacía preferibles los referentes de la Meseta. La historia nacional no era ya la de la monarquía, sino la de la lucha por la libertad frente al despotismo interno y la opresión extranjera y ello tenía su reflejo en las calles. El pasado nacional se ponía al servicio de un proyecto político y su recreación generaría otra comunidad imaginada. La nación española era sometida a un intenso proceso de recreación política, simbólica y cultural en base a las necesidades del presente; el progresismo se había embarcado en la invención de la tradición ${ }^{27}$, y aunque la composición del Ayuntamiento alicantino $^{28}$ no nos permite hablar de un dominio progresista, el moderantismo no pudo abstraerse de muchos referentes míticos progresistas, mucho menos en una ciudad de clara filiación liberal como Alicante.

Es necesario destacar la política seguida en torno al Barrio Nuevo, puesto que sus calles de reciente construcción, largas, anchas y de gran habitabilidad,

27. ROMEO MATEO, M. C., «La tradición progresista: historia revolucionaria, historia nacional», en SUÁREZ CORTINA, M. (ed.), La redención del pueblo. La cultura progresista en la España liberal, Universidad de Cantabria, Santander, 2006, pp. 106-109 y 111-113.

28. DíAZ MARín, P., op. cit., pp. 158-164. A la altura de 1852, el alcalde Tomás España y concejales como Bergez, Carratalá, Ibarra o Roman muestran el control municipal por parte de la burguesía comercial y agraria moderada. 
son reservadas para hechos relacionados con la Guerra de la Independencia y los sacrificios llevados a cabo por la libertad. Así, nos encontramos con las paralelas calles de Bailén y Castaños, la batalla y su vencedor, que se cruzan con el recuerdo del asedio de Gerona, en una calle de importancia por conectar la Plaza de San Francisco con las cercanías de la Plaza de la Constitución. Con esto se resaltaba la importancia de la Guerra de la Independencia como el símbolo de la unidad española, siendo por ello el punto de referencia inapelable para la consolidación del sentimiento nacional español y constituyéndose como elemento básico de la cultura nacional con sus héroes y batallas ${ }^{29}$. Era el mito integrador por excelencia, siendo aceptable tanto para los liberales (el pueblo interviene para redimir la tiranía) como para los conservadores (el pueblo fiel a las creencias y tradiciones) ${ }^{30}$.

Al norte del Barrio Nuevo encontramos un recordatorio a los mártires de la libertad que habían muerto luchando por la implantación del liberalismo, destacando la presencia de aquellos caídos durante la Década Ominosa. La extensa calle Riego, que conectaba la Plaza del Teatro con el extremo oeste de la muralla, se cruzaba con las calles dedicadas a los pronunciamientos «románticos» de la década de los 20, tanto el de los hermanos Bazán (1826), como el de Torrijos (1831). Una menor importancia en el plano tenía el recuerdo de la intentona del coronel Valdés (1824), que completa la remembranza de la lucha política contra el absolutismo hasta 1833. Más hacia el oeste, se recordaban las esencias nacionales, puesto que la calle Navas, que mostraba la unión ante el invasor, se cruzaba con la calle de Colón.

A nivel global, podemos observar cómo de una ciudad con una presencia testimonial de la tipología política, pasamos a la Alicante de mediados de siglo, que tenía un $46,4 \%$ de calles rotuladas con esos nombres. Pese a la invasión del paisaje urbano con referentes de tipo político, se respetó la tradición religiosa, como muestran las 38 calles de tipo religioso, que conforman un $30,4 \%$ del paisaje urbano, destacando en el casco antiguo. Las denominaciones funcionales, 29 (23,2\% del total) son las que más retroceden, perdiendo más de la mitad de sus denominaciones por varias razones. Éstas habían sido denominaciones populares que fueron sustituidas por el control de la Comisión de Ornato. Además, con las alineaciones geométricas y las obras de urbanización y mejora de calles, cada vez era más complicado encontrar elementos físicos de la calle que permitieran distinguirla de otras, por lo que su uniformidad restringió la expansión de esta tipología.

29. A.A.V.V, Historiografía y nacionalismo español (1834-1868), CSIC, Madrid, 1985, pp. 189-194.

30. Álvarez JunCO, J., op. cit., pp. 226. 
Todo ello muestra cómo el liberalismo triunfante consiguió imponer su visión del paisaje urbano como elemento de pedagogía política, siendo el Barrio Nuevo el ejemplo paradigmático. Así, el callejero alicantino de 1852 se nos muestra irremisiblemente ligado a la historia como no había pasado en forma alguna hasta el momento; concretamente, el callejero no era ni más ni menos que una traslación de la interpretación liberal de la historia de España, que pasaba a ocupar un lugar de privilegio en el paisaje urbano con una intencionalidad pedagógica, con la que se pretendía formar y fomentar la conciencia nacional de la recién creada nación. Así pues, las calles tenían una labor educativa entre la población, instruyéndolas en la antigüedad de la nación y su historia. Una vez que el callejero superó una fase inicial en que fue escenario de lucha de ideas, el Estado liberal mostraba sus posibilidades como educador y productor de sociabilidad a través del paisaje urbano, ya que no debemos olvidar que la denominación de las calles es una de las manifestaciones más claras de la memoria colectiva de una comunidad tendente a configurar una determinada identidad.

\section{El Sexenio Democrático}

La autorización concedida por el Ministerio de la Guerra en 1858 para que Alicante derribara sus murallas permitió a la ciudad pasar de la tradicional ciudad amurallada a la ciudad abierta, aunque el derribo material de las murallas no comenzó hasta $1869^{31}$. La transformación física de la ciudad debe ser explicada, entre otros factores, por la teatralidad del poder burgués, que necesitaba representar materialmente su dominio en el espacio público ${ }^{32}$. La visita de Isabel II en mayo de 1858, además de mostrar la nueva conexión que Alicante disfrutaría con Madrid gracias al ferrocarril, reflejó cómo el Paseo de la Reina iba perdiendo importancia como centro de reunión de las elites alicantinas, puesto que allí se producía el contacto con el pueblo llano. En cambio, el teatro era una plasmación perfectamente válida para la burguesía

31. Derribo de las murallas que era concebido como motor de transformaciones, oportunidad de beneficios individuales y de acción organizada y coordinada, y, en general, como el impulso a cambios sociales, económicos, culturales y políticos. A falta de estructura industrial, las transformaciones urbanísticas generan procesos similares a los históricamente vinculados con el advenimiento de aquella, en términos de «clase» y «control social». En la ciudad de Valencia, permitió una reapropiación del centro urbano por parte de la burguesía con la excusa de las ideas higienistas. Ver PONS, A., SERNA, J., op. cit., pp. 16 y 114.

32. Ibídem, pp. 103-107 y 240-245. 
Cuadro 7. Cambios 1868

\begin{tabular}{|l|l|}
\hline Nombre antiguo & Nuevo nombre \\
\hline Princesa & Prim \\
\hline Aparicio & Cádiz \\
\hline Subida a la puerta de la Reina & Zaragoza \\
\hline Infanta & Alcoy \\
\hline Puerta de la Reina & Puerta de Alcoy \\
\hline Plaza de Isabel II & Plaza de la Libertad* \\
\hline Paseo de la Reina & Paseo de Méndez Núnez \\
\hline Explanada & Paseo de los Mártires* \\
\hline
\end{tabular}

* Sugerencias de la Junta Revolucionaria

porque cada grupo social debía ocupar un lugar jerarquizado, de ahí que se convirtiera en un reflejo de la sociedad de clases $^{33}$.

Así, no fue casualidad que las barricadas de septiembre de 1868 se levantarán frente al Teatro Principal. Ya el 9 de octubre encontramos disposiciones relativas a las calles, acordándose diversas variaciones de nombre ${ }^{34}$, con las que el Sexenio borraba del callejero a la recién expulsada monarquía (ver cuadro 7). Además, también se atendió a las sugerencias de la Junta Revolucionaria, que acordó «la denominación de Paseo de los Mártires con que el pueblo designó el de la explanada el día del glorioso alzamiento» ${ }^{35}$.

Encontramos ocho cambios de nombre de claro contenido político, seis de los cuales se utilizaron para eliminar el recuerdo de la monarquía, incluida la referencia al pintor de cámara de Fernando VII. Interesante es resaltar las diferencias entre la clase política de los años 50 y 60 a través de la diferente aceptación del pintor Aparicio. Se entronizará a Prim, el militar revolucionario y líder del partido progresista y a Méndez Núñez, pasando por los nombres de Cádiz y Zaragoza, ciudades míticas desde 1814. El simbolismo de sustituir la Plaza de Isabel II por la de la Libertad también es sintomático de los nuevos tiempos. Finalmente, asistimos a la construcción del mito progresista más potente en Alicante hasta la II República, el de los Mártires de la Libertad ${ }^{36}$, al

33. Lloret I ESQUERDO, J., (1998), El Teatre a Alacant 1833-1936, Generalitat Valenciana, Valencia, p. 42. Más de la mitad de las localidades estuvieran destinadas al público más adinerado.

34. A.M.A., Cabildo 9 de octubre de 1868, arm. 9, lib. 167.

35. A.M.A., Cabildo 12 de octubre de 1868, arm. 9, lib. 167.

36. Diaz Marín, P. y Fernández Cabello, J. A, Los mártires de la libertad. La revolución de 1844 en Alicante, Instituto de Cultura Juan Gil-Albert, Alicante, 1992. 
que se dedicó un paseo y un monumento que recordara a los mártires ${ }^{37}$, incluyendo también a los muertos en 1826, 1848 y 1868 por defender la libertad ${ }^{38}$.

La importancia que tenía la nomenclatura de las calles llevó a que se retomara el debate con el advenimiento de la República. En junio de 1873 el regidor Marcili protestó por que no se hubiera procedido a quitar la lápida de la Constitución sustituyéndola por otra que «dijese Plaza de la República Federal». Finalmente, se acordó que la Comisión de Ornato propusiera la variación de nombres de calles «sustituyéndolos con nombres ilustres de la República» ${ }^{39}$. Ese trabajo probablemente no llegó a realizarse, puesto que los cambios de la Restauración contemplan únicamente las modificaciones reseñadas. De esta forma, las ideas republicanas suponían una ruptura con la mentalidad liberal, puesto que no se sentían representadas con el concepto de Constitución tanto como con el de República Federal; de ahí la intención de modificar el paisaje urbano en esa plaza, el punto inicial de las políticas de apropiación del espacio público por parte de los republicanos, como en su día lo fue de los liberales.

\section{La Restauración}

En los momentos iniciales de la Restauración encontramos la eliminación de la obra del Sexenio. Así, «a propuesta de la Comisión de Ornato y teniendo en cuenta los grandes inconvenientes que ofrece la variación de los antiguos nombres de las calles, se acordó que la calle de Prim recobre su antiguo nombre de la Princesa, la Plaza de la Libertad el de Isabel II, la Puerta de Alcoy de la Reyna, y la calle de Alcoy de la Infanta; respetando el nombre del Paseo de Méndez Núñez por ser el de una gloria patria» ${ }^{40}$.

Escudándose en la utilidad de mantener los nombres de las calles, se restauraron la mitad de las modificaciones, en concreto, las referidas a la monarquía. Por otra parte, hay que destacar que la Restauración mantuvo el recuerdo de la Guerra de Independencia (calles Cádiz y Zaragoza) junto con el de Méndez Núñez, útiles desde la perspectiva nacionalizadora. Por otro lado, el Paseo de los Mártires, mito bien arraigado en Alicante, pervivió por haber sido asumido como un referente común por el liberalismo alicantino. La Restauración modificó únicamente los nombres que no podía aceptar bajo ningún concepto.

37. A.M.A., Cabildo 30 de octubre de 1868, arm. 9, lib. 167.

38. A.M.A., Cabildo 9 de noviembre de 1868, arm. 9, lib. 167.

39. A.M.A., Cabildo 11 de junio de 1873, arm. 9, lib. 172.

40. AMA, Cabildo 8 de enero de 1875, arm. 9, lib. 174. 
Cuadro 8. Desapariciones 1881

\begin{tabular}{|l|l|l|}
\hline Funcional & Religiosa & Política \\
\hline Aduana* & Almas & Aparicio \\
\hline Plaza del Mar & Monjas & Infanta* $^{*}$ \\
\hline Puerta de la Huerta & Plaza del Carmen & Montalvo \\
\hline Puerta del Muelle & Plaza de San Carlos & Plaza de Campoamor* \\
\hline Subida de la calle Toledo & Puerta de San Francisco & Puerta de la Reina (calle) \\
\hline & San Andrés* & Puerta de la Reina \\
\hline & San Antón & Reina \\
\hline & Virgen de los Desamparados & Ribera* $^{*}$ \\
\hline & Virgen del Grito & Valdés* $^{*}$ \\
\hline
\end{tabular}

* Nombres dictaminados por la Comisión de Ornato (1852)

Buena prueba de ello es que de los 144 nombres reflejados para 1852 , únicamente desaparezcan 23, el 15,9\% de las denominaciones, en 1881 (ver cuadro 8). Ello refleja un consenso liberal burgués, puesto que sólo 6 de las desapariciones eran nombres surgidos del dictamen de la Comisión de Ornato. Así, es evidente que el callejero de 1852 era válido para las elites de 1881, puesto que una parte importante de las desapariciones lo son por necesidad, como ejemplifican las denominaciones relacionadas con las murallas recién derribadas. Cabe destacar cómo la tradicional Plaza del Mar vio cambiado su nombre por el de Plaza de Alfonso XII, de forma que uno de los espacios urbanos más emblemáticos, por su relación espacial con las casas consistoriales, pasó a glorificar a la monarquía restaurada.

Globalmente, Alicante constaba aproximadamente en 1881 de 15 plazas y 166 calles. De éstas, al menos 60 tenían nombres novedosos con respecto a 1852, debiéndose tener en cuenta que 20 eran producto de la aplicación (en 1862) de la R.O de 24 de febrero de 1860 que sustituía los rótulos en valenciano por otros en castellano, lo que se aprovechó para introducir nuevos nombres de clara índole liberal ${ }^{41}$.

De las 60 vías novedosas, 25 corresponden al recién asimilado barrio de San Antón (ver cuadro 9), que sólo desde 1868 formaba parte de la ciudad de forma oficial. La configuración de sus calles nos muestra una destacada presencia funcional, explicada porque este barrio no sufrió modificaciones

41. Ramos, V., Crónica de la Provincia de Alicante, Diputación de Alicante, Alicante, 1979, p. 331. 
Cuadro 9. Novedades San Antón 1881

\begin{tabular}{|l|l|l|l|}
\hline Funcional & Religiosa & Política & Cultural \\
\hline Pozo & Concepción & Trafalgar* & Desengaño* \\
\hline Parroquia & $\begin{array}{l}\text { Plaza de la } \\
\text { Misericordia }\end{array}$ & Sevilla* & Esperanza* $^{*}$ \\
\hline Gallo & & Valencia & Gloria* \\
\hline Nueva alta & & Empecinado * & Olvido* \\
\hline Nueva baja & & Espoz y Mina * & Paraíso* $^{*}$ \\
\hline Platos & & Paseo de Quijano & Peligros* \\
\hline Huerta & & $\begin{array}{l}\text { Paseo Duque de la } \\
\text { Victoria }\end{array}$ & Travesía del Olvido \\
\hline Hospital del Rey & & Plaza de Quijano & \\
\hline
\end{tabular}

* Calles nombradas en 1862

en 1852. En cuanto a las calles de tipo cultural (ver mapa 3), están ligadas al impacto del movimiento romántico en la ciudad.

Un proceso similar se da en el Arrabal Roig, donde encontramos 9 novedades (ver cuadro 10), algunas sólo administrativamente (por ser calles existentes desde 1794 pero no reflejadas a nivel oficial), ya que en la década de 1880 la ciudad en expansión se había fijado en el abandonado barrio y modernizó el nombre de sus calles. Pese a que conserve una importante impronta de nombres funcionales, ya se incluyen entre ellos nombres de tipo político. Así pues, casi el 60\% de las novedades del periodo quedan concentradas en estos dos espacios que no habían sufrido la actuación de la Comisión de Ornato en 1852, por lo que los nombres de sus calles fueron actualizados o reconocidos administrativamente en este momento.

En pleno centro urbano surgirán las calles Mártires y Méndez Núñez, frente a los paseos homónimos, mostrando una de las herencias más importantes del Sexenio. Así, el callejero muestra el carácter moderado de la Restauración, pero también la voluntad de conciliar e integrar a cierto progresismo para unirlo a la defensa de la monarquía constitucional ${ }^{42}$. A su vez surgirá una calle dedicada a un ilustre vecino, José María Muñoz (1814-1890), soldado extremeño que destacó por sus obras caritativas en la ciudad. En el Barrio Nuevo sólo surge una nueva denominación, en 1862, dedicada a Golfín, prisionero

42. SuÁREZ CoRTINA, M., «Introducción. Las tradiciones culturales del liberalismo español, 1808-1950», en SuÁrez Cortina, M. (ed.), Las máscaras de la libertad. El liberalismo español 1808-1950, Marcial Pons Historia, Madrid, 2003, p. 27. Sagasta consiguió recuperar parte de la herencia del Sexenio y el callejero lo refleja perfectamente. 
Cuadro 10. Novedades Arrabal Roig 1881

\begin{tabular}{|l|l|l|}
\hline Funcional & Religiosa & Política \\
\hline Lavadero de Santa Ana & Socorro (1794) & Madrid* $^{*}$ \\
\hline Cantera & Santa Ana (1794) & Lope de Vega* \\
\hline Primer Callizo de la Sierra & & Jovellanos* \\
\hline $\begin{array}{l}\text { Segundo Callizo de la } \\
\text { Sierra }\end{array}$ & & \\
\hline
\end{tabular}

* Calles nombradas en 1862

en el castillo de Santa Bárbara en 1814 y primer gobernador civil tras ser declarada Alicante provincia. Su trayectoria nos explica que frente a un Muñoz que ocupa una calle en el casco antiguo, Golfin obtenga un espacio en el lugar de privilegio de la ciudad.

Donde había estado la Alameda de San Francisco desde 1834, siguiendo el trazado de la carretera de Madrid, surgieron nuevas calles tras el derribo de las murallas. Las primeras que allí se crearon, en 1862, recibieron los nombres de Ramales, Quiroga y Pasaje de París; junto a una muestra de localismo, Quiroga recuperó una calle y se rememoró la última gran batalla de la guerra carlista. Este espacio quedaba articulado junto con la gran calle de Luchana (otra batalla de la guerra civil) en base a referentes liberales y anticarlistas.

Gracias al plano de 1881 observamos los cinco paseos que la ciudad de Alicante tenía. En los inicios de siglo, únicamente existía el Paseo del Enlosado, ante las Casas Consistoriales, pero en la década de los 80 encontramos el Paseo de los Mártires, el Paseo de Méndez Núñez, el Paseo de Quijano, el Paseo del Duque de la Victoria (denominación que desde 1855 y hasta 1895 recibió el antiguo Paseo de Campoamor) y el Paseo de la Libertad. Además, a éstos tenemos que añadir por sus funciones la calle de Luchana, acondicionada como paseo desde 1892. Pese a la importancia del paseo urbano como manifestación de la sociabilidad burguesa y del ascenso social conseguido, el eje lúdico de la ciudad se fue ligando a la Explanada y demás lugares de recreo próximos al $\operatorname{mar}^{43}$; elemento que se vería acentuado con la creación a principios del siglo XX del Paseo de Gomis, a través del cual se accedía a los frecuentados balnearios. Con el advenimiento de la sociedad de masas, la primacía de que habían

43. Figueras PacheCO, F., Geografía General del Reino de Valencia, Barcelona, vol. 5 (circa 1913), p. 414. 
gozado los paseos como eje de sociabilidad se fue perdiendo, al compás de los teatros de verano, los circos y otras diversiones populares.

En síntesis, el callejero de 1881 refleja el alto grado de consenso que había generado entre las elites alicantinas la situación de 1852. Pero el crecimiento que había desbordado el antiguo perímetro de las murallas nos muestra nuevos nombres, en un momento en que la población había superado los 34.926 habitantes censados en 1877. La mitad de las novedades del momento fueron de carácter político, destacando el mantenimiento residual de las calles de tipología funcional, que ocupan el 23,3\% de las nuevas denominaciones. Pese a todo, es sintomático que la mitad de éstas se concentren en el Barrio de San Antón. A su vez, en estos momentos se confirma la falta de atractivo de los nombres religiosos a la hora de rotular las calles, componiendo únicamente el $15 \%$ de las novedades.

Por otro lado, es conveniente resaltar la aparición de los nombres de tipo cultural. Hay que distinguirlos de la tipología política, que utiliza la cultura como medio para formar la nación. En cambio, los nombres culturales constituyen un fin en sí mismos, reflejando el gusto romántico de una parte de la sociedad alicantina. Aunque sólo representan el 11,6\% de las novedades, es fundamental señalar cómo ello muestra hasta qué punto el callejero fue siendo apropiado por la dinámica del presente.

Si analizamos globalmente el callejero de 1881, encontramos que aproximadamente el $47,4 \%$ de sus calles son de índole político, lo que indica que pese al crecimiento del número de vías de la ciudad, la proporción se mantuvo con respecto a 1852. Las denominaciones religiosas ocupan el 25,6\% del espacio urbano, mostrando un descenso aproximado del $5 \%$ en importancia cuantitativa. A nivel cualitativo, el descenso es mayor si tenemos en cuenta cómo estas denominaciones son relegadas al casco histórico, y es que una vez desamortizadas las propiedades de la Iglesia, también se produjo una «desamortización simbólica» del paisaje urbano. Los nombres funcionales representan el 22,9\% de las denominaciones de 1881, manteniéndose en proporciones similares a las de 1852. Finalmente, la irrupción de las calles de tipo cultural, aunque ocupe únicamente el $4 \%$ de la ciudad, nos muestra la influencia de la discutida generación romántica alicantina ${ }^{44}$ y la interrelación del callejero con la sociedad del momento.

El crecimiento urbano de Alicante llevó a que en 1883 se autorizara la edificación del barrio de Benalúa por parte de la Sociedad Anónima de los

44. Ríos Carratalá, J. A., Románticos y provincianos. La literatura en Alicante 1839-1886, Universidad de Alicante, Alicante, 1986, pp. 27-36. 
Diez Amigos, integrada por miembros de la burguesía local bajo la presidencia del Marqués de Benalúa. Éste se ubicaría en la parte occidental del Ensanche siguiendo los criterios higienistas. En este contexto de crecimiento (ver mapa 4) surgiría la convocatoria en enero de 1887 de un concurso para formular el ensanche de la ciudad. En abril de 1893 se aprobaba el proyecto general de González Altés, situado al norte y oeste del casco antiguo, empleando calles ortogonales que delimitaban manzanas cuadrangulares, en base a dos ejes con dirección norte-sur (Luchana) y este-oeste (Alfonso el Sabio) ${ }^{45}$.

Sin embargo, este ensanche difirió mucho de la teoría y la práctica de los ensanches, estando relacionado con esa idea únicamente por su morfología ortogonal ${ }^{46}$. Por otra parte, el capital de las clases acomodadas comenzó a invertirse en la mejora de infraestructuras y comunicaciones de la urbe en expansión, que gracias a la especulación se convirtió en un negocio en sí mismo $^{47}$. En 1889 se adoquinaba la calle San Francisco, generalizándose la opinión sobre la necesidad de pavimentar todas las calles ${ }^{48}$.

Este panorama de expansión urbana explica que frente a los cambios de nombre de 1852, en este caso las nuevas denominaciones sean producto del crecimiento de la ciudad, que contaba en 1910 con 55.300 habitantes. Además, en 1913 podemos valorar ya de forma bastante completa el impacto que la Restauración había tenido en el callejero, ya que el Ensanche permitía nombrar una gran cantidad de nuevas calles, por lo que tuvo una dimensión simbólica, implicando 66 nuevos nombres de vías.

El barrio de Benalúa contuvo 19 de las 66 nuevas denominaciones, mostrando una absoluta primacía de los nombres políticos, 16 en total (ver cuadro 11). Éstos se dedicaron a la exaltación y recuerdo de los componentes de la junta directiva de la Sociedad, convirtiendo el barrio en un vehículo para el lucimiento de sus constructores, que se aseguraron un espacio en el paisaje urbano. También se reservó el espacio privilegiado de la plaza del barrio para el político alicantino Navarro Rodrigo, Ministro de Fomento que hizo valer

45. A.A.V.V., Sobre la ciudad dibujada de Alicante: del plano geométrico al plan general de 1970, Colegio Oficial de Arquitectos de Valencia, Delegación de Alicante, Alicante, 1985, pp. 13-16.

46. NavarRo Vera, J. R., «El paisaje territorial y urbano», Canelobre, no 43 (2000-2001), p. 128 y 129.

47. Vidal Olivares, J., Comerciantes y políticos (Alicante 1875-1900), Instituto de Estudios Juan Gil-Albert, Alicante, 1987, pp. 83-98.

48. Ramos Hidalgo, A., Evolución urbana de Alicante, Instituto de Estudios Juan Gil Albert, Alicante, 1984, p. 206. 
Cuadro 11. Benalúa 1913

\begin{tabular}{|l|l|l|l|}
\hline $\begin{array}{l}\text { Exaltación de la } \\
\text { Sociedad de los Diez } \\
\text { Amigos }\end{array}$ & Favores políticos & $\begin{array}{l}\text { Recuerdo a la } \\
\text { Antigüedad }\end{array}$ & Alicantinos ilustres \\
\hline Aguilera & $\begin{array}{l}\text { Plaza de Navarro } \\
\text { Rodrigo }\end{array}$ & Quintiliano & Foglietti \\
\hline Alberola & & Illice & Just \\
\hline Carratalá & & & Mingot \\
\hline Soler & & & \\
\hline García Andreu & & & \\
\hline Pardo Jimeno & & & \\
\hline Pérez Medina & & & \\
\hline Aguilera & & & \\
\hline Doscientos & & & \\
\hline Arquitecto Guardiola & & & \\
\hline Arquitecto Morell & & & \\
\hline
\end{tabular}

su influencia, ampliando los límites del Ensanche para incluir el barrio de Benalúa en junio de $1887^{49}$.

Otro sector que aglutinó las novedades del periodo fue la zona del Ensanche, ocupando el 30,3\% de las novedades con sus 20 denominaciones (ver cuadro 12). La importancia de estas nuevas calles explica que 19 fueran de tipo político, y sólo 1 fuera dedicada a la exaltación de motivos religiosos (el obispo Castellar). Hay que reseñar la importancia del eje simbólico creado por las calles Serrano, Prim y O'Donnell, que cruzaban a la calle Libertad. El mensaje de las elites era evidente; la libertad estaba asociada a militares monárquicos. El sector al sur de la Avenida de Maisonnave no tenía la misma importancia a nivel urbanístico en sus calles, y por ello se reservó la mayor parte de ese espacio para los hijos de la ciudad. Pese a todo, es significativo que dos figuras políticas locales (Maisonnave y Gadea) reciban grandes avenidas que articularían en un futuro la ciudad.

Pese a que los dos grupos que acabamos de estudiar componen el 60\% de las nuevas denominaciones encontramos otros casos interesantes. En la urbanización del barrio de San Fernando surgen cinco calles y todas son de tipo político, haciendo referencia a la cultura del Siglo de Oro (Calderón de la Barca, Velázquez, Juan de Herrera, Murillo y Padre Mariana) mostrando con ello la diversidad de nomenclaturas en función del interés urbanístico de cada zona.

49. A.A.V.V., Sobre la ciudad dibujada..., p. 15. 
Cuadro 12. Ensanche 1913

\begin{tabular}{|l|l|l|l|c|}
\hline Reyes y nación & Cultura y nación & $\begin{array}{l}\text { Alicantinos } \\
\text { ilustres }\end{array}$ & $\begin{array}{l}\text { Los mártires } \\
\text { de la libertad } \\
\text { y la Guerra de } \\
\text { Independencia }\end{array}$ & $\begin{array}{l}\text { Militares, } \\
\text { orden y } \\
\text { libertad }\end{array}$ \\
\hline Alfonso el Sabio & $\begin{array}{l}\text { Avenida de } \\
\text { Zorrilla }\end{array}$ & $\begin{array}{l}\text { Avenida de } \\
\text { Maisonnave }\end{array}$ & $\begin{array}{l}\text { Plaza de la } \\
\text { Independencia }\end{array}$ & Serrano \\
\hline & Plaza de Balmes & $\begin{array}{l}\text { Avenida del } \\
\text { Doctor Gadea }\end{array}$ & Libertad & Prim \\
\hline & Cervantes & Belando & Zurbano & O'Donnell \\
\hline & & $\begin{array}{l}\text { Abd el Hamet * } \\
\text { Churruca }\end{array}$ & \\
\hline & & $\begin{array}{l}\text { Lorenzo } \\
\text { Casanova * }\end{array}$ & & \\
\hline & Castellar * & & \\
\hline & & Loases * & & \\
\hline & & Barrejón * & & \\
\hline & & Cano Manrique * & & \\
\hline
\end{tabular}

* Sector sur del Ensanche

Al sur de Benalúa surgen tres vías de tipo político (Isabel la Católica, Trajano, Salamanca), destacando la última, futura gran avenida con la que se pagaban los servicios del político que tan importantes apoyos había conseguido para la llegada del ferrocarril a Alicante. Al final de la avenida surgió el Parque de Canalejas, dedicándose un espacio urbano de importancia al político nacional que pasaba por benefactor de la ciudad. En el casco histórico destaca que se sitúe al final del Paseo Méndez Núñez una plaza dedicada a Emilio Castelar, por ser un republicano inserto en el régimen. Por otro lado, resurge el nombre tradicional de Postiguet, perdido en 1852, y que se recuperó tras las obras conducentes a la creación del Paseo de Gomis.

Debemos destacar 7 cambios de nombre (ver cuadro 13) que muestran la confluencia entre el uso político tendente a asegurar espacios tradicionales a la monarquía con una nueva modalidad de apropiación del paisaje urbano, en la que los dirigentes de los principales partidos políticos ocupaban en vida un espacio en la ciudad, pese a las restricciones legales al respecto ${ }^{50}$. Estos cambios de nombre nos muestran el mundo político de la Restauración, que

50. Los abusos llevaron a que las R.O. del Ministerio de Gobernación (18 de marzo de 1904 y 10 de febrero de 1905) prohibieran terminantemente el cambiar el nombre de una vía pública. En caso de que se cambiara, no podía ser en beneficio de una persona fallecida en un plazo de diez años, requiriéndose para tal acto la conformidad de dos terceras partes de los propietarios de la vía. 
Cuadro 13. Cambios de nombre 1913

\begin{tabular}{|l|l|}
\hline Nombre antiguo & Nombre nuevo \\
\hline Plaza de San Francisco & Plaza de la Reina Victoria \\
\hline Princesa & Rafael Altamira \\
\hline Babel & Rafael Terol \\
\hline Bóvedas & Canalejas \\
\hline San Francisco & Sagasta \\
\hline Paseo Duque de la Victoria & Paseo de Campoamor (1895) \\
\hline Puerta de Alcoy & Zaragoza \\
\hline
\end{tabular}

invadió con la política del presente el paisaje urbano; proceso particularmente visible en los casos de Canalejas, que recibe una calle, una plaza y un parque por su sólida red clientelar en Alicante ${ }^{51}$, José Gadea, concejal y alcalde en el periodo 1893-1903, Rafael Terol o Sagasta.

La política había cambiado y con ello la utilización de las calles también se transformó. Si las calles habían sido un elemento de construcción nacional, con la consolidación de la Restauración jugaron un nuevo papel, basado en la exaltación de las elites políticas y del sistema existente. Las limitaciones legales al respecto nos muestran hasta qué punto el callejero comenzó a ser utilizado como moneda de cambio para el pago de favores políticos.

Analizando globalmente el callejero de 1913, observamos que sólo 27 de las calles presentes son de tipo funcional, lo que supone el 14,8\% del total, una importante caída respecto a 1881; reducción que no podemos desligar del impacto del Ensanche y reformas urbanas como el desmonte de la Montañeta. En cuanto a las calles de tipología religiosa, encontramos 37, lo que representa el 20,3\% del total, mostrando una caída reseñable con respecto a 1881. Que plazas emblemáticas como la de San Francisco cambien su nombre en función de la coyuntura política nos muestra que ni las denominaciones religiosas tenían garantizada su existencia si ocupaban espacios urbanos relevantes. Por último, 114 de las 182 calles son de tipo político, lo que nos muestra el final del proceso de afianzamiento de esta tipología. De una representación anecdótica en 1814 al dominio completo del paisaje urbano con un 62,6\% de las vías; dominio visible en las novedades del periodo, puesto que el $83,3 \%$ fueron políticas.

51. Forner, S. y Garcia M., Cuneros y caciques, Patronato Municipal del V Centenario de la ciudad de Alicante, Alicante, 1990, p. 18. 
Cuadro 14. Nombres del barrio de Carolinas (1920)

\begin{tabular}{|l|l|}
\hline Nombre antiguo & Nuevo nombre \\
\hline Vereda & Jaime Segarra \\
\hline Jericó & Doctor Buades \\
\hline Rodrigo Soriano & Cronista Viravens \\
\hline Terol & Chapalangarra \\
\hline Zarandieta & Conde Lumiares \\
\hline Serra & 8 de marzo \\
\hline Rosa & Jacinto Maltés \\
\hline Sol & Carlos Arniches \\
\hline Luna & Antonio de Trueba \\
\hline Azucena & General Espartero \\
\hline Calera & General Serrano \\
\hline & Avenida de la Libertad \\
\hline
\end{tabular}

Únicamente el 9\% de las novedades del periodo fueron religiosas, en lo que influyó el peso del progresismo y republicanismo alicantino, y un exiguo $7,5 \%$ de calles nuevas recibieron un nombre de tipo funcional. Es revelador que en todas las denominaciones novedosas relacionadas con el Ensanche no aparezca ni una sola denominación funcional, puesto que la denominación funcional había quedado a nivel mental relacionada con las sucias calles del Antiguo Régimen. Por ello, en la ciudad del Ensanche la extinción de los nombres funcionales se vio como una muestra más de progreso.

A su vez, siguió en auge la utilización de las vías urbanas para exaltar el localismo. En 1920, se aprobaba la moción del concejal Llorca tendente a eliminar «los nombres de calles bautizadas por algún vecino sin más pauta que su capricho, huérfanos en la mayoría de casos de ingenio y faltos de lógica» ${ }^{52}$ del barrio de Carolinas (ver cuadro 14), quedando patente que los vecinos comenzaban a intervenir en la denominación de sus calles ${ }^{53}$. Las ocho primeras calles son denominadas con motivos locales, y aunque algunos tengan un claro simbolismo político (8 de marzo y los mártires de la libertad, Chapalangarra) la mayoría recuerda a los alicantinos ilustres. Únicamente Antonio de

52. A.M.A., Sección Policía Urbana, Leg. 42/20, 31 de marzo de 1920.

53. Así, en febrero de 1917 unos vecinos de la calle Socorro propusieron dedicar su calle al literato Joaquín Dicenta. Poco después, otros vecinos y la Cofradía de Nuestra Señora del Socorro escribían al Ayuntamiento en contra de esa idea. Finalmente, la Comisión de Ornato mantuvo el nombre de la calle por los transtornos que generaban los cambios de nombre. A.M.A., Sección Policía Urbana, Leg. 40/48, 26 de febrero de 1917. 
Trueba recuerda una figura literaria nacional, configurando este barrio como un espacio dedicado al localismo.

\section{Consideraciones finales}

El panorama trazado nos ha permitido observar el paulatino cambio en la utilización del paisaje urbano, puesto de manifiesto en la diferente concepción del callejero de 1852 frente al de 1913. Así pues, la utilización de la denominación de las calles aparece como un elemento en constante transformación, de forma que los procesos de modernización social ofrecen ejemplos de la variante relación entre el callejero y la sociedad.

Las calles sufrieron el impacto del luto colectivo bélico en 1921, cuando se decidió dar los nombres de siete oficiales alicantinos fallecidos en la guerra africana a las travesías de la carretera de San Vicente junto con la antigua calle subida al castillo de San Fernando ${ }^{54}$. Así se ocupaba el espacio público para conformar opinión, en base al culto a los caídos entendidos como encarnación del Pueblo ${ }^{55}$.

En la década de los 30 el callejero pasó a ser una de las primeras preocupaciones populares. En 1931, un alicantino se quejaba de la calle escogida para honrar a Salmerón, demandando al Ayuntamiento que se le diera una vía más céntrica, a la par que proponía diversos nombres de republicanos ilustres que merecían una calle ${ }^{56}$. La sociedad de masas y las clases populares tuvieron un importante impacto en el proceso de utilización política del callejero, ya que se estaba decidiendo qué memoria colectiva y qué identidades se deseaba conservar. La democratización también había llegado al callejero, como se podría comprobar durante la II República y la Guerra Civil, momentos en que la implicación popular en la denominación de las calles fue total ${ }^{57}$.

No quisiera concluir sin remarcar que pese a la fuerza legal de las decisiones del Ayuntamiento y de la Comisión de Ornato, el papel popular en la denominación de las calles tuvo una importancia que desgraciadamente no ha quedado reflejada en la mayoría de las fuentes. Esto es visible en parte gracias a los testimonios contemporáneos, que reflejan las costumbres populares en lo referido a la designación callejera ${ }^{58}$. Los alicantinos siguieron utilizando la

54. AMA, Cabildo 15 de octubre de 1921, arm. 9, lib. 221, fol. 12v y 13.

55. SERRANO, C., op. cit., pp. 220-221. Su capítulo dedicado a la fabricación del héroe Cascorro, en 1896, muestra formas novedosas de movilización de la opinión durante la Restauración, cuyos ecos encontramos aquí.

56. A.M.A., Cabildo 16 de abril de 1931, arm. 9. lib. 236, fol. 104.

57. NAVARRO NAVARRO, J., op. cit., pp. 94-103

58. Figueras PacheCO, F, op. cit., p. 367, 382, 385, 408, 415 y 428. 
nomenclatura funcional de Explanada para el oficial Paseo de los Mártires, como también sucedía con la Plaza de Alfonso XII, conocida popularmente como Plaza del Mar. A su vez, la denominación Paseo del Duque de la Victoria para el Paseo Campoamor tampoco tuvo mucho éxito. En casos menos emblemáticos también se manifestó este fenómeno, de forma que la calle Calatrava se siguió denominando como Balseta, mientras que la calle San Vicente fue bautizada popularmente como de los Árboles; al igual que la de la Vereda, conocida por el nombre del republicano Sol y Ortega. Por último, la ironía popular se mostró en denominaciones como Gran Vía para el pequeño Paseo del Doctor Soler.

En conclusión, y pese a los distintos usos que se pudiera dar al callejero de tipo político, éste pasó de una representación anecdótica cien años atrás al dominio completo y absoluto del paisaje urbano con fines diversos, mostrando uno de los efectos del juego político liberal con mayor importancia a la hora de construir la memoria de nuestra sociedad, como podemos comprobar diariamente. 


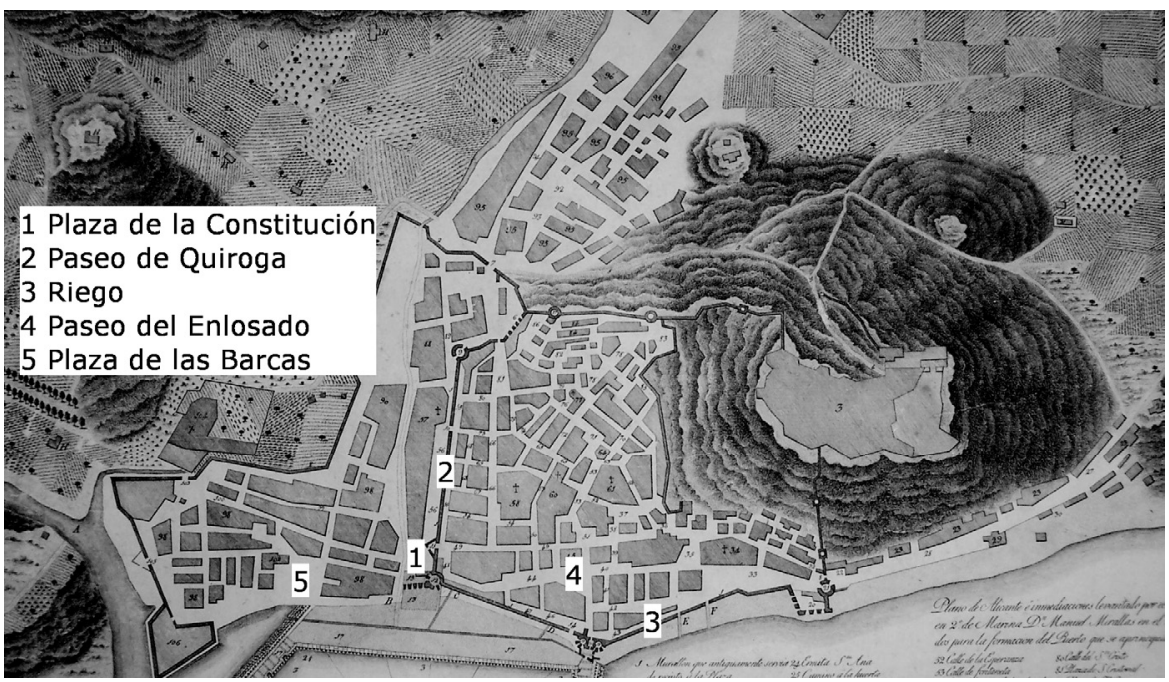

Mapa 1. Plano de Alicante e inmediaciones levantado por Manuel Miralles en 1794. Detalle.

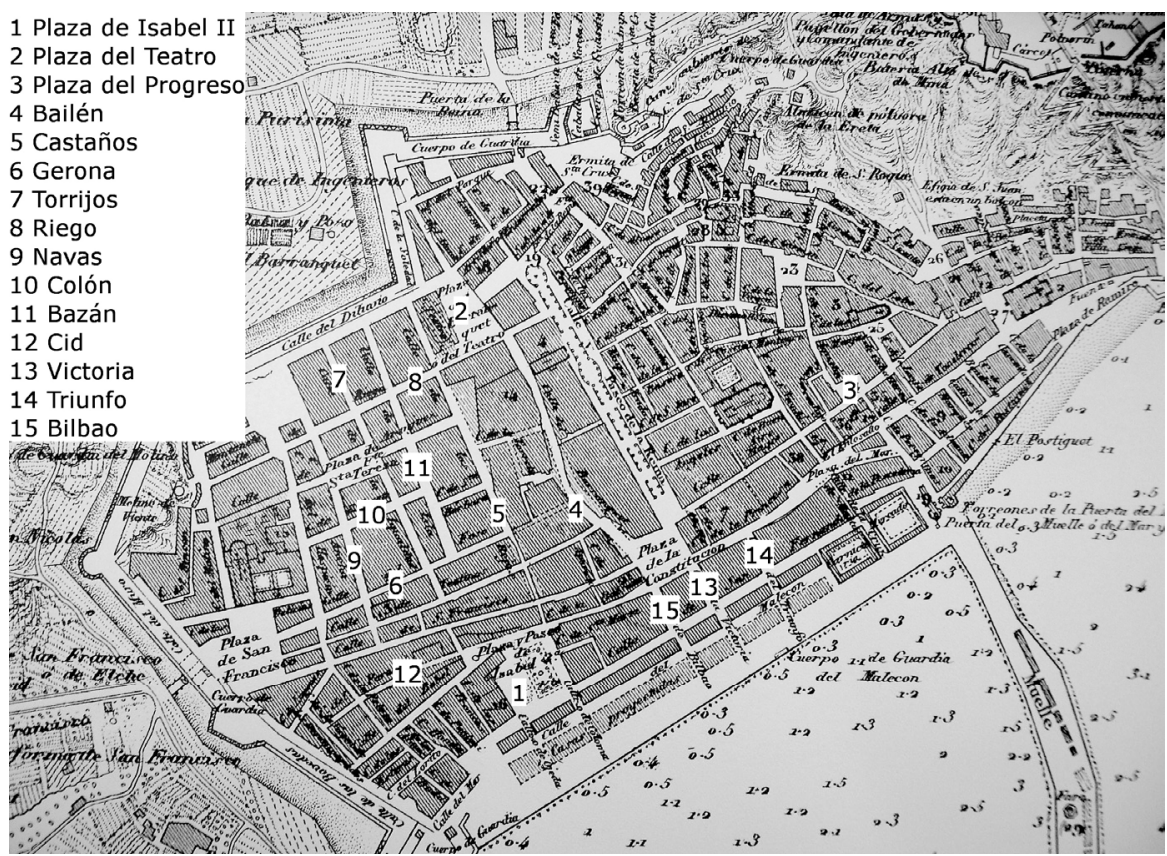

Mapa 2. Plano de la ciudad de Alicante, levantado por Francisco Coello (1853). Detalle. 


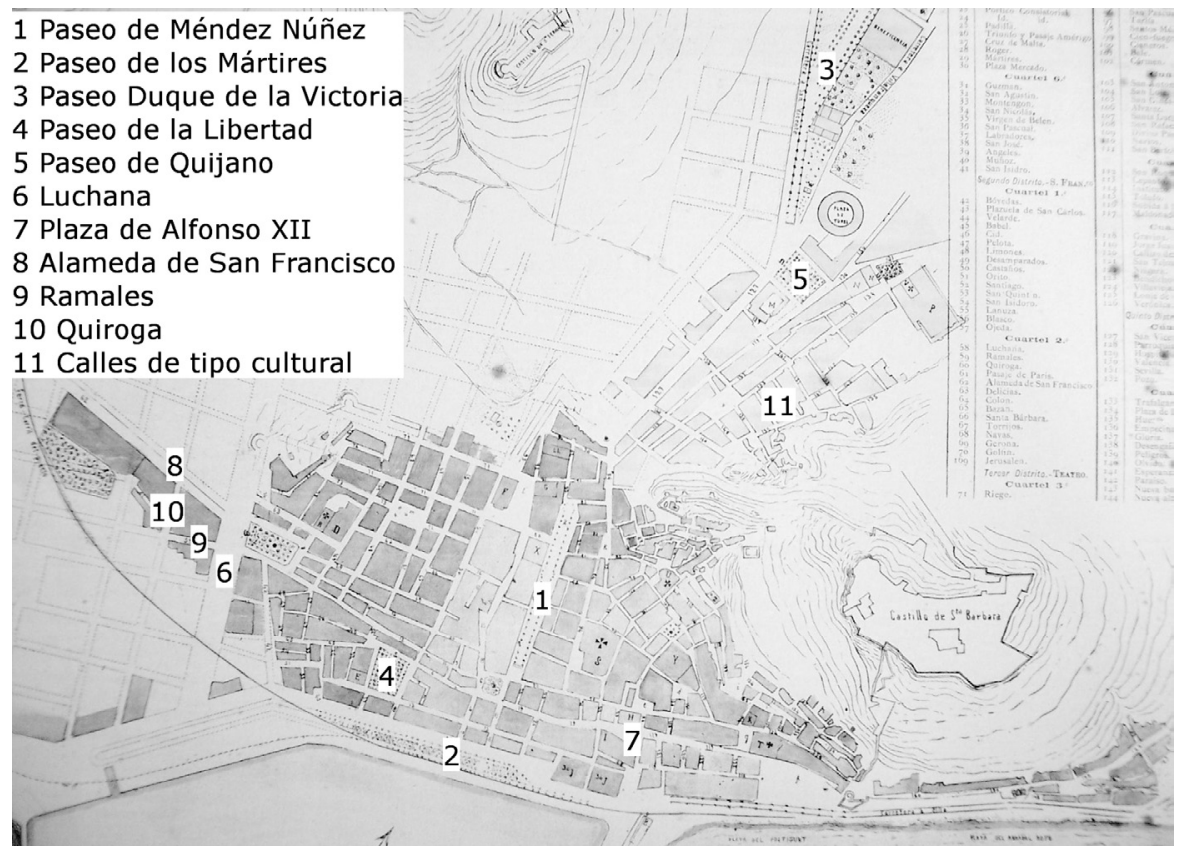

Mapa 3. Plano de la ciudad de Alicante (1881). Detalle.

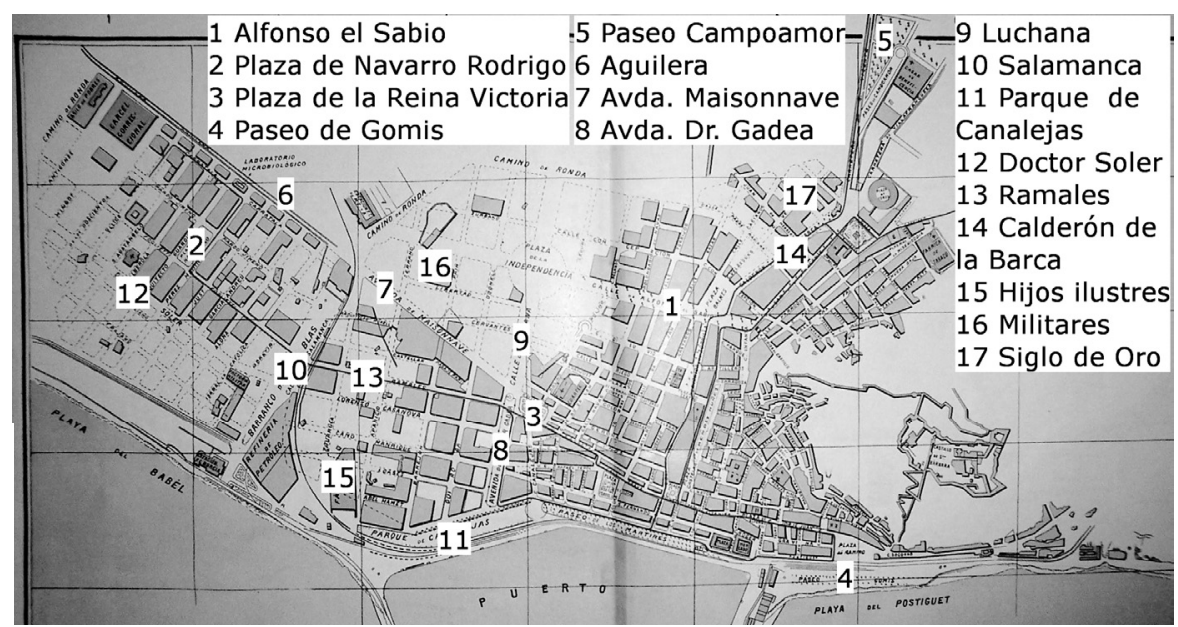

Mapa 4. Ciudad de Alicante (circa 1913). Detalle. 